Review article

\title{
Prevalence and risk factors of female genital mutilation in Egypt: a systematic review
}

\author{
Ahmed Arafa ${ }^{\mathrm{a}, \mathrm{b}, *}$, Alshimaa Mostafa ${ }^{\mathrm{c}, \mathrm{d}}$, Ehab S. Eshak ${ }^{\mathrm{a}, \mathrm{e}}$ \\ ${ }^{a}$ Department of Public Health, Graduate School of Medicine, Osaka University, Osaka, Japan \\ ${ }^{\mathrm{b}}$ Department of Public Health, Faculty of Medicine, Beni-Suef University, Beni-Suef, Egypt \\ ${ }^{\mathrm{c}}$ Department of Dermatology, Graduate School of Medicine, Kyoto University, Kyoto, Japan \\ ${ }^{\mathrm{d}}$ Department of Dermatology and Venereology, Faculty of Medicine, Beni-Suef University, Beni- Suef, Egypt \\ ${ }^{\mathrm{e}}$ Department of Public Health, Faculty of Medicine, Minia University, El-Minia, Egypt
}

A R T I C L E I N F O

\section{Keywords:}

Egypt

Epidemiology

Female genital mutilation

Prevalence

Risk factors

\begin{abstract}
A B S T R A C T
Background: Female genital mutilation (FGM) is an ancient practice with several physical, emotional, and sexual complications. This study aimed to investigate the prevalence and risk factors of FGM in Egypt via systematic review.

Methods: According to the checklist of PRISMA, we systematically retrieved studies that assessed FGM prevalence among various Egyptian samples from different scientific databases.

Results: FGM prevalence in the included studies $(\mathrm{n}=36)$ ranged between $14.7 \%$ and $100 \%(66.2 \%-100 \%$ in the hospital-based studies and $14.7 \%-86.9 \%$ in the student-based studies). FGM prevalence has been showing a declining trend throughout the previous decades. Low parental education and rural residence were identified as major risk factors for FGM. Social, religious, and hygienic drives were shown to enhance the continuation of the practice.

Conclusion: FGM prevalence in Egypt, though not precisely detected, seems to be enormous. Understanding the social and religious drives of FGM can help in its elimination.
\end{abstract}

\section{Introduction}

Female genital mutilation (FGM), also referred to as female genital cutting or female circumcision, is a term used to describe partial or complete excision of the external female genitalia for non-therapeutic reasons. ${ }^{1}$ FGM has many types ranging from excision of the prepuce with/out clitoris (Type I or Clitoridectomy) and excision of the clitoris and labia minora (Type II or Excision) to profound excision of the external genitalia with stitching and tightening the vaginal opening (Type III or Infibulation). Type IV describes pricking, piercing, scraping, and cauterization of the external genitalia without flesh removal. ${ }^{2}$ In societies with Muslim majorities, type I is known as "Sunna Circumcision"; a religious term linking the practice to the commands of the Prophet of Islam or "Khifad" the Arabic synonym of "reduction"; a term claiming that the Prophet of Islam endorsed partial rather than complete excision of the external genitalia. ${ }^{3}$ In Egypt, types I and II are also called "Tahara"; the Arabic synonym of "purification" which points to the hygienic drive of the practice. ${ }^{4}$

FGM is endemic in Sub-Saharan and Northern African countries, ${ }^{5}$ yet it is also encountered in Europe,,${ }^{6,7}$ Australia, ${ }^{8}$ and the USA ${ }^{9}$ through the immigrants who brought their culture. However, the spread and determinants of the practice differ significantly across the countries. In Egypt, FGM is deeply entrenched in the beliefs and values of the society due to many social and religious factors. ${ }^{10}$ Even though the law in Egypt penalizes people who perform and people who request FGM with hefty fines and even jail, ${ }^{11}$ the Egyptian Demographic Health Surveys (EDHSs) for the years 1995, 2000, 2003, 2005, 2008, and 2014 showed that the practice in the country was almost universal. ${ }^{12-17}$ Regardless of its prevalence, the physical and psychological complications of FGM in Egypt were shown to be enormous. These complications are usually categorized into primary or acute complications and secondary or longterm complications. The primary complications include pain, bleeding, and psychiatric trauma while the secondary complications include several emotional, menstrual, and sexual disorders. ${ }^{18-20}$

Although FGM is known to be widespread across the country, its exact prevalence is not identified. Many studies investigated the epidemiology of FGM among various populations in Egypt but reached conflicting results and drew inconsistent conclusions. The unawareness

\footnotetext{
* Corresponding author. Department of Social Medicine, Osaka University Graduate School of Medicine, Suita-shi, Osaka, 565-0871, Japan.

E-mail address: Ahmed011172@med.bsu.edu.eg (A. Arafa).
} 
of the real magnitude of FGM in addition to the complexity of the drives behind its continuation seem to curb the efforts of developing national risk-prevention strategies with the purpose of eliminating FGM. Herein, we systematically collected studies that investigated the prevalence and risk factors of FGM in Egypt.

\section{Methodology}

\subsection{Search strategy}

This systematic review was reported according to the checklist of PRISMA. $^{21}$ We retrieved studies that investigated FGM prevalence among Egyptian women and were published in English or Arabic languages before 30/11/2018. Studies were collected from the following scientific databases: PubMed, Google Scholar, and the Egyptian Knowledge Bank. We used the following search terms: (Female genital mutilation OR Female circumcision OR Female genital cutting OR Female genital excision OR Infibulation OR Clitoridectomy) AND (Egypt). The Arabic translates of these search terms were used to collect the Arabic studies.

\subsection{Study selection}

Our initial research retrieved 1258 articles, then we eliminated the duplicates to reach 512 articles. Later, we manually screened the abstracts to include studies that assessed FGM prevalence among Egyptian women. In this step, we excluded studies without abstracts $(\mathrm{n}=18)$, studies that did not assess FGM prevalence $(n=404)$, studies that assessed FGM among non-Egyptian samples $(\mathrm{n}=46)$, and books and editorials $(n=8)$ to reach a final list of 36 articles (Fig. 1). All included studies were published in English since the reviewed Arabic studies focused on investigating the social correlates with FGM rather than its prevalence. No efforts were done to access unpublished reports. The articles included in the final list were reviewed and the following data were extracted: first name of the first author, publication year, study location, number and age of participants, prevalence, risk factors, drives, complications, and study limitations.

Potentially relevant studies identified by

preliminary research of PubMed,

PubMed, Google Scholar, and the

Egyptian Knowledge Bank ( $\mathrm{n}=1258$ )

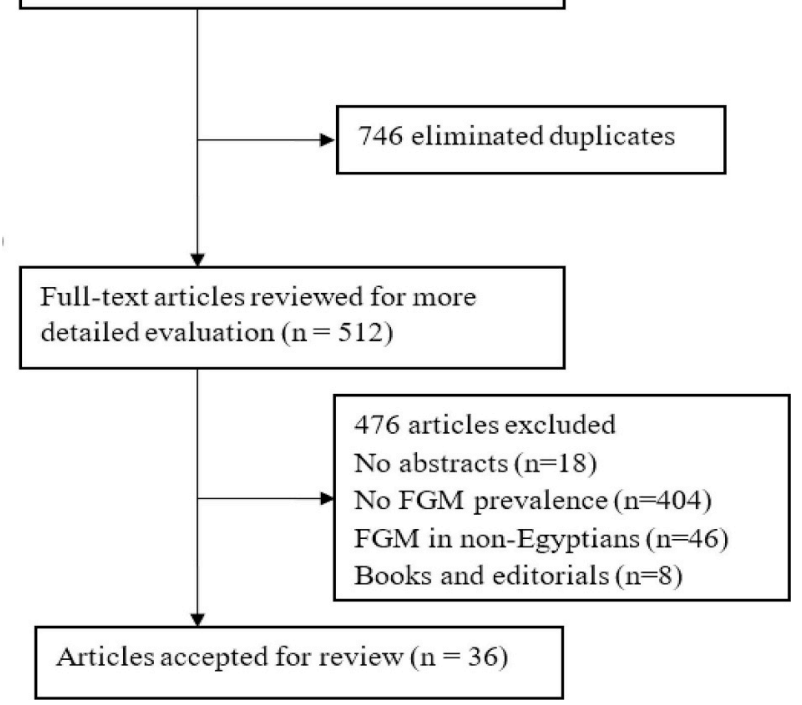

Fig. 1. Flow chart of the study selection process.

\section{Main findings}

\subsection{FGM prevalence and its decreasing trend}

A total of 36 cross-sectional studies investigated FGM prevalence in Egypt during the period between 1980 and 2018. Twelve studies were conducted in North Egypt and put the prevalence between 14.7\% and 92\%, 15 studies were conducted in South Egypt and put the prevalence between $47.3 \%$ and $100 \%$, and 9 studies (including 6 EDHSs) representing the whole country put the prevalence between $50.2 \%$ and $97 \%$. Yet, the prevalence rates in the EDHSs were significantly higher than other studies that represented the whole nation; $91 \%-97 \%$ versus $50.2 \%-64.8 \%$, respectively. The hospital- and student-based studies together contributed to $40 \%$ of the total studies with FGM prevalence ranging between $66.2 \%$ and $100 \%$ in the hospital-based studies and $14.7 \%-86.9 \%$ in the student-based studies (Table 1) (Fig. 2).

It should be noted that a declining FGM prevalence throughout the previous decades has been detected. For example, FGM prevalence in the EDHSs decreased from $97 \%$ in 2003 to $92 \%$ in 2014 amongst the ever-married women. ${ }^{14-17}$ FGM prevalence in the EDHSs 2008 and 2014 was lower among women (15-24 years) compared with older women. ${ }^{16,17}$

On the other hand, more obvious drops were noticed in other epidemiological studies. For example, recent studies conducted on populations from North and South Egypt ${ }^{18,22}$ showed much lower rates of FGM compared with earlier studies. ${ }^{10,23}$ These drops are thought to be attributed to decreased illiteracy, FGM criminalization, and official and non-official campaigns that aim to raise the awareness about FGM. ${ }^{24}$

\subsection{Factors affecting FGM prevalence}

\subsubsection{Socio-demographic variations}

The variations in the socio-demographic characteristics of the investigated populations had significant impacts on the estimated FGM prevalence. Since FGM is tightly related to low socio-economic standards, ${ }^{22}$ studies conducted on populations residing in the deprived governorates of South Egypt showed a higher FGM prevalence than that reported in North Egypt. ${ }^{12-17}$ A nationwide study conducted on 38,816 schoolgirls showed that FGM prevalence in South Egypt was almost double that of North Egypt. ${ }^{25}$

Besides, low parental education and rural residence or origin were detected as significant risk factors of FGM in Egypt. In a study conducted on householders, $92 \%$ of mothers of the circumcised daughters were illiterate compared with $69 \%$ of the uncircumcised. ${ }^{26}$ Another study concluded that rural residence of adolescent girls doubled their risk of exposure to FGM. ${ }^{18}$ A study conducted on university students showed that illiteracy rates among parents of the circumcised girls were $11.4 \%$ for fathers and $23.1 \%$ for mothers compared with $2.5 \%$ and $3.6 \%$ among fathers and mothers of the uncircumcised girls, and $53.9 \%$ of the circumcised girls were residing in rural areas compared with $16.4 \%$ in the uncircumcised group. ${ }^{24}$ Other studies from North and South Egypt reached similar conclusions. ${ }^{22,23,27,28}$

\subsubsection{Study location}

Ten studies were conducted on patients or their relatives who were attending public hospitals for different reasons. These studies showed a higher FGM prevalence compared with other epidemiological studies. In two hospital-based studies, Al-Hussaini found that all nulliparous women coming for delivery were circumcised ${ }^{10}$ and Assad reported an FGM prevalence of $90.8 \%$ among women attending a family planning center. ${ }^{29}$ Unlike hospital-based studies, FGM prevalence among university students was considerably lower than that reported in other epidemiological studies. For example, one study used a multi-stage random sampling method to include 1723 university students and reported a $47.3 \%$ FGM prevalence. ${ }^{24}$ Another study conducted on 313 medical students put FGM prevalence at $14.7 \% .^{30}$ 


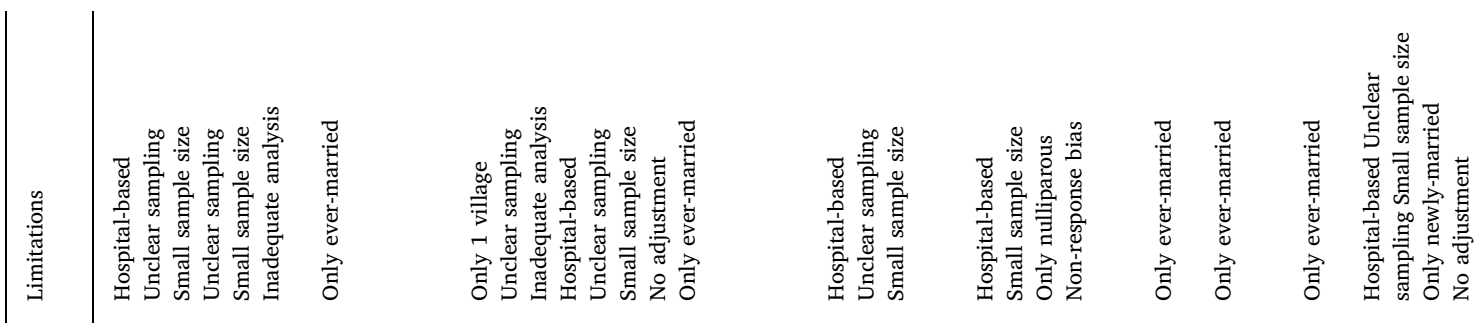

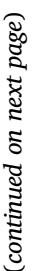

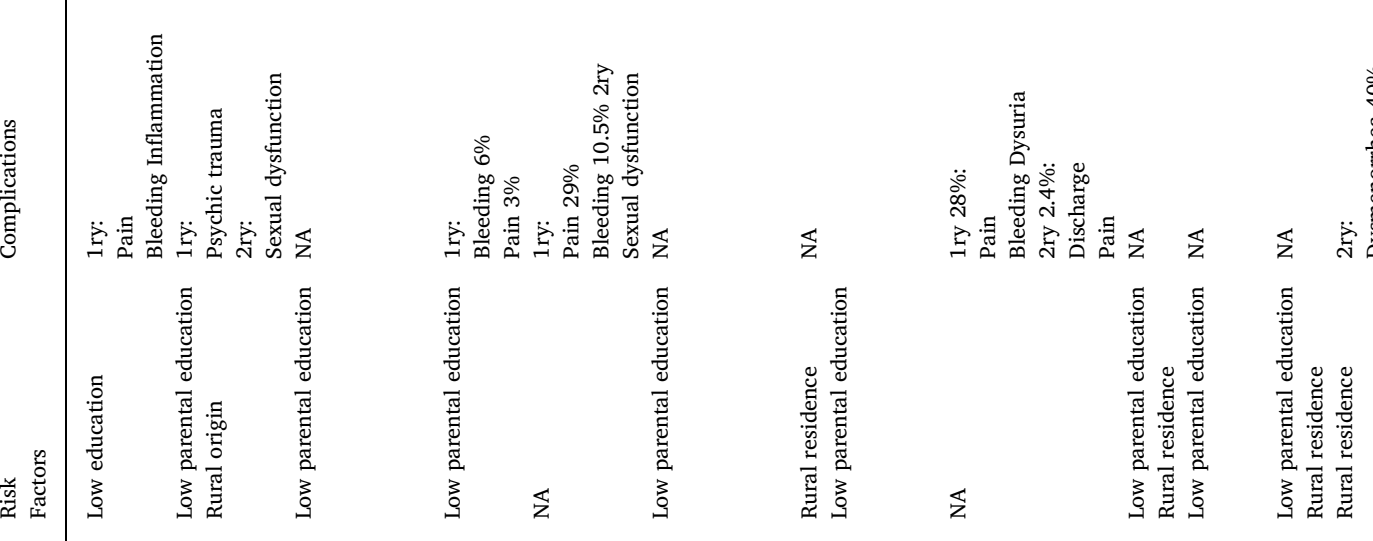

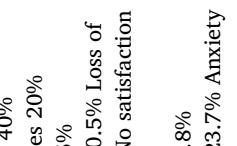

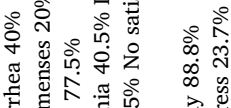

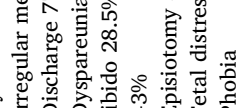

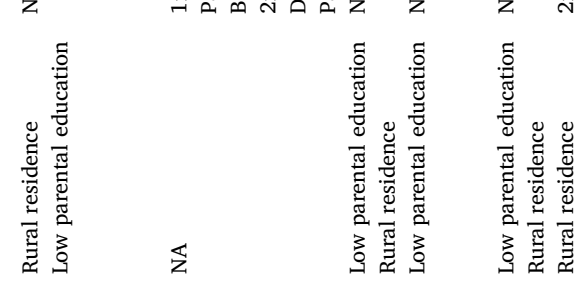

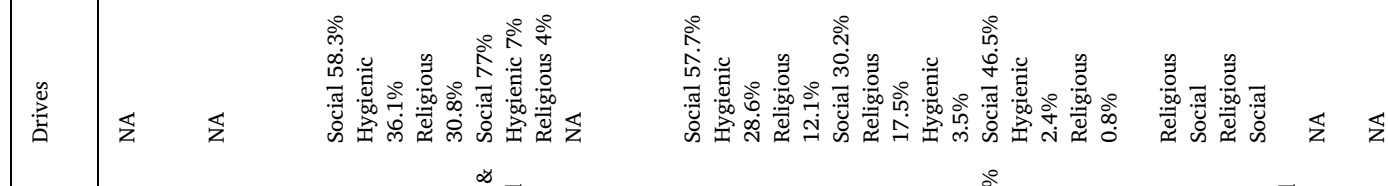

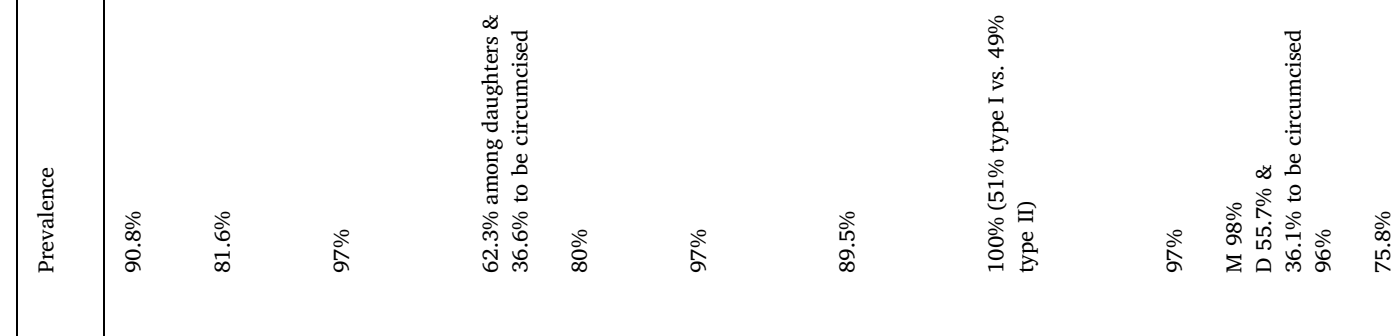

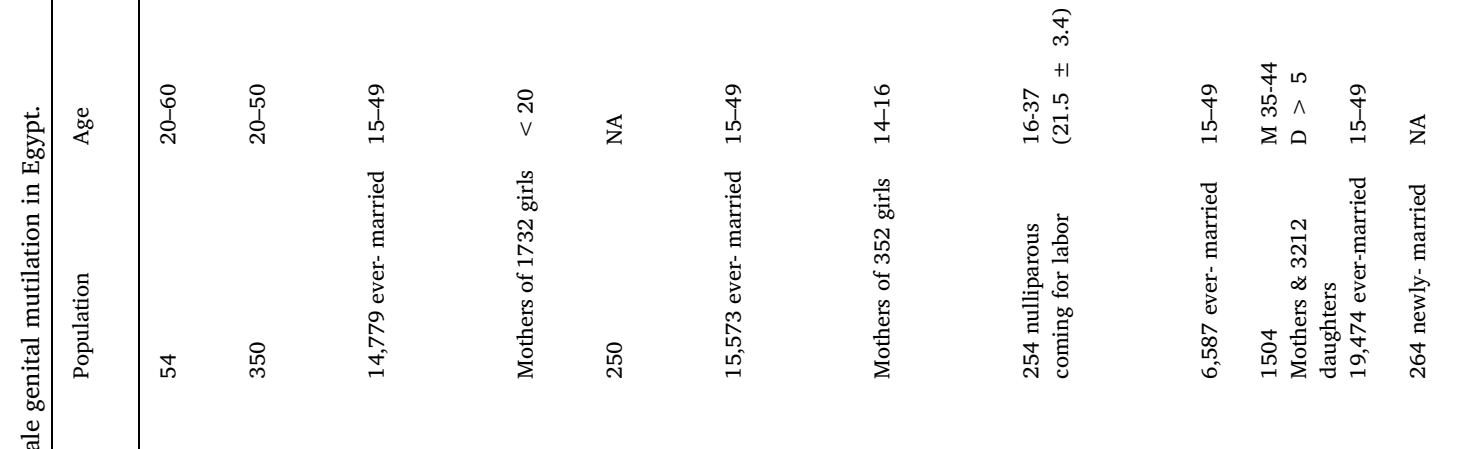

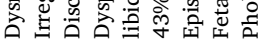




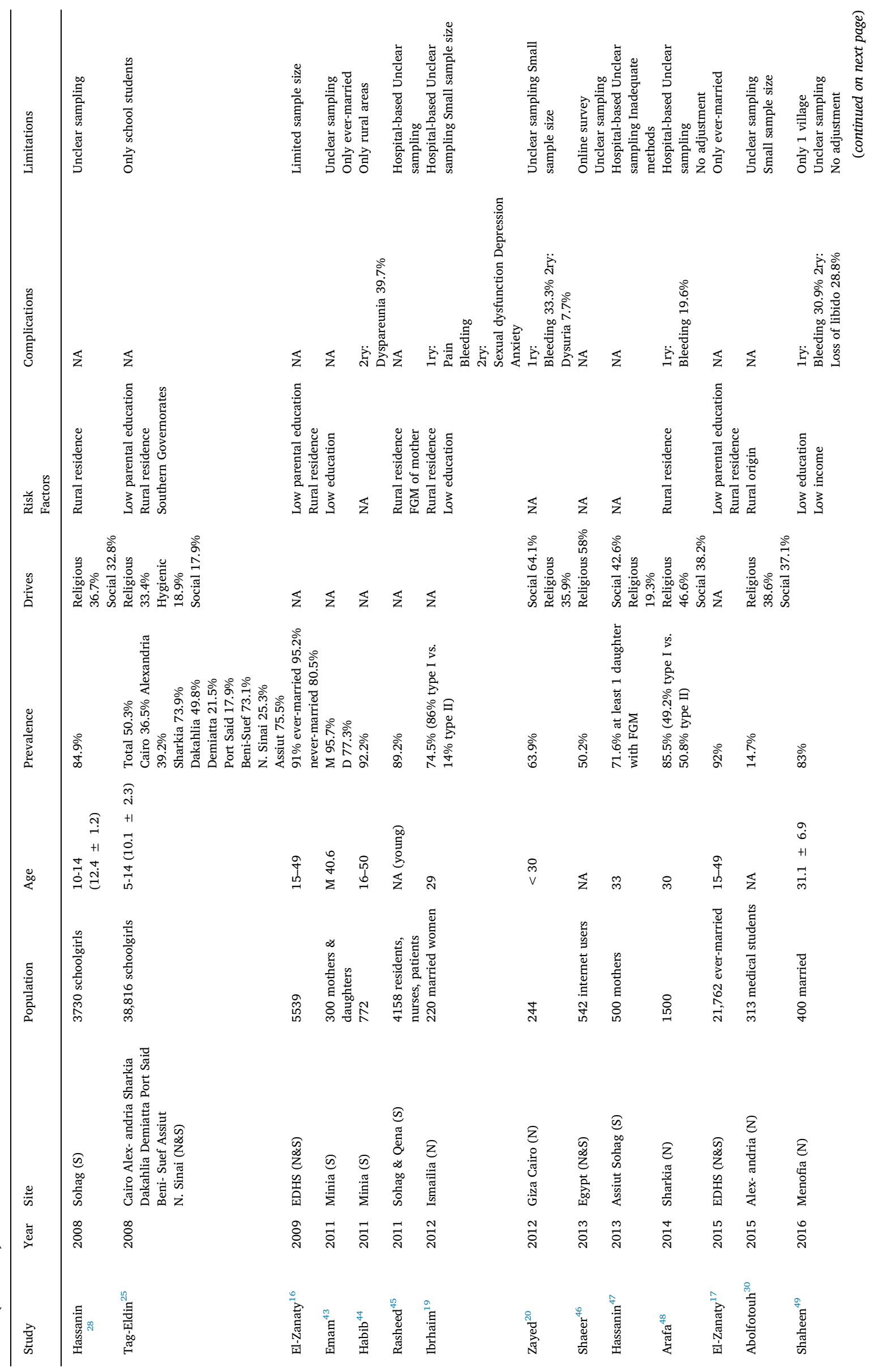




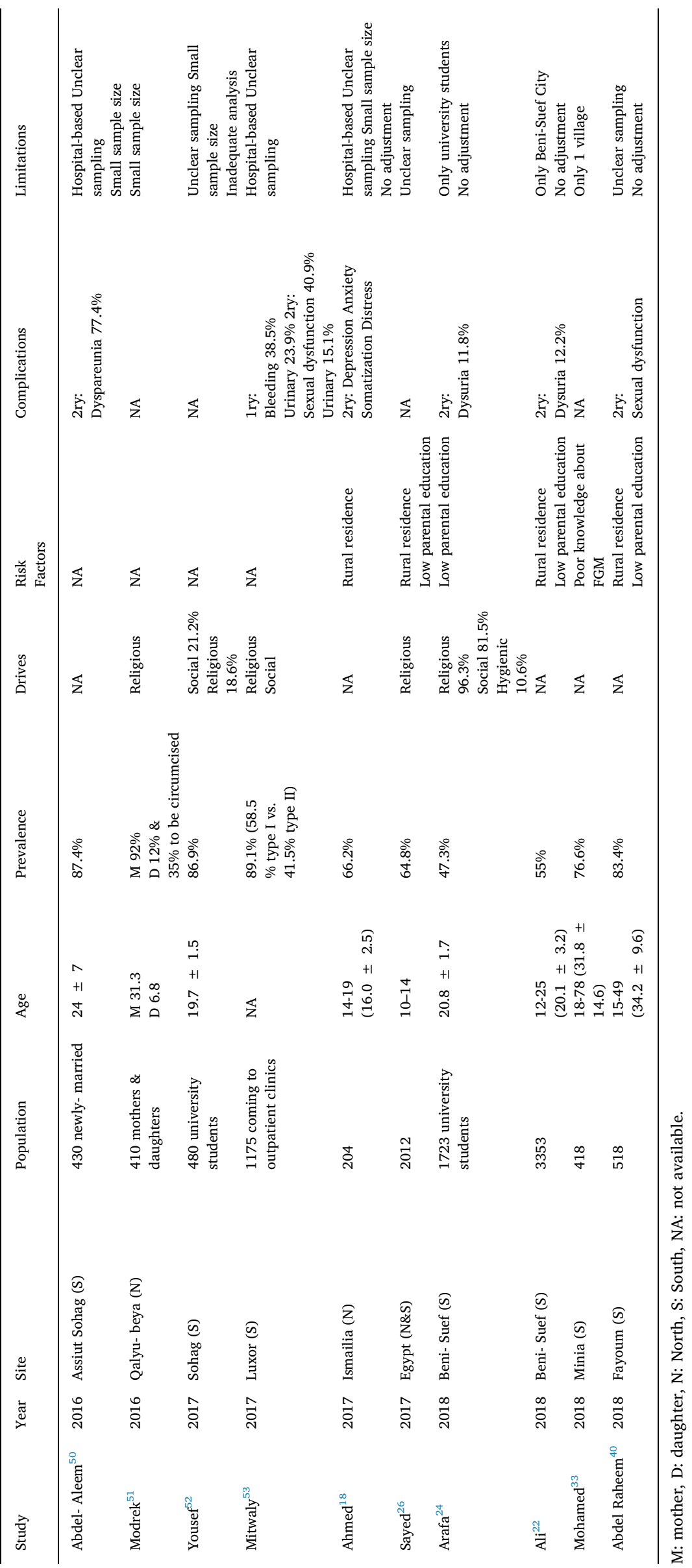




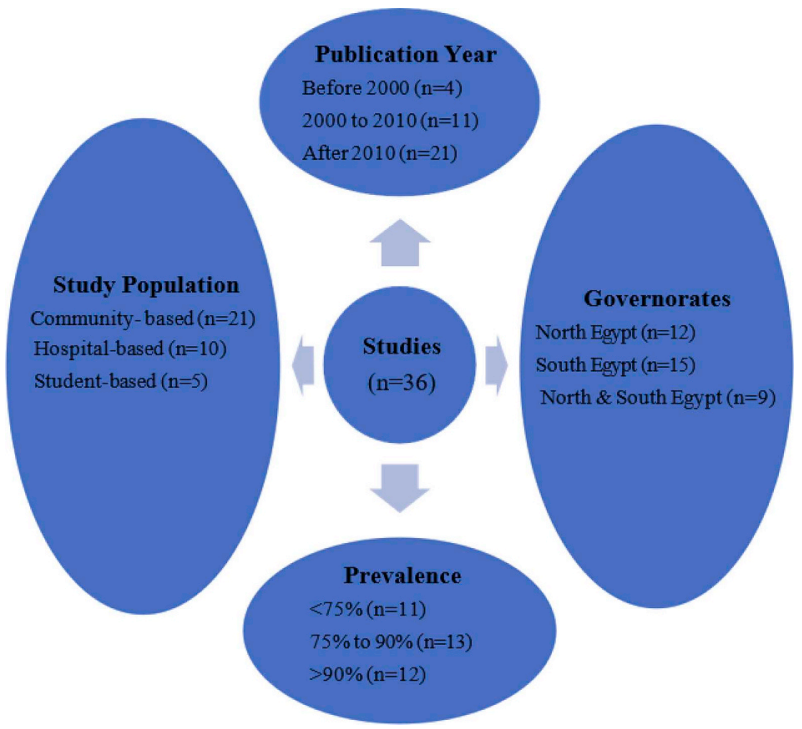

Fig. 2. Distribution of studies by socio-demographic characteristics, publication year, and FGM prevalence.

\subsection{Drives}

The list of FGM drives in Egypt can be shortened to social, religious, and hygienic drives.

These drives were primarily ignited by two important risk factors: low education and rural residence.

\subsubsection{Social drives}

Socially, FGM practice is not widely condemned and parents of the circumcised children and FGM practitioners do not consider the practice a type of physical violence. People often accept FGM as a normal milestone of the woman's life. Some parents are even accused of negligence in case of omitting FGM and face substantial social pressure to get their young daughters circumcised. ${ }^{31}$

Moreover, there is a strong association between FGM and the accepted moral standards of the woman in rural communities. These moral standards determine the chances of the young girls in doing well in the marriage market. Uncircumcised girls are thought to have lower marriage opportunities because it is socially unacceptable for men to marry uncircumcised women. ${ }^{32}$ A recent study showed that $71.4 \%$ of men preferred circumcised wives, and accordingly, women in this rural community were supportive of the continuation of FGM even more than men; $60.3 \%$ versus $47.9 \%$, respectively. ${ }^{33}$

Van Rossem et al. analyzed the education, labor market participation, and literacy of women included in the EDHSs in relation to their attitudes towards FGM and found that the improvement of women's social position was associated with anti-FGM attitudes. The authors suggested that the disadvantaged social position of women in Egypt paved the way to the continuation of FGM in the context of the societal gender inequality. ${ }^{31}$

However, the change of the attitude might not be sufficient to curb the practice without improving the parental education. Educated parents pose a stronger social position in the rural community compared with the low or non-educated members. This privileged position enhances the autonomy of parents' decision and makes them more loyal to family than community traditions. When parents, especially mothers, become less guided by social traditions, they are more likely to oppose FGM. Over time, the educated parents will cast a collective choice abandoning FGM. ${ }^{31}$

\subsubsection{Religious drives}

Many people believe that the goal of FGM is to attenuate the sexual desire of women to agree with the moral view of Islam. But, this claimed religious moral view may be no more than a translation of the social view in the country because FGM is not practiced among the Muslim populations in Gulf countries; meanwhile, it is practiced by Christians in Egypt. In a rural area in South Egypt, $47.3 \%$ of Muslims versus $30 \%$ of Christians described FGM as a good practice that should be continued. ${ }^{33}$

Many contradictions were noticed among the views of the Muslim preachers and religious leaders regarding FGM. In 1950, the Grand Mufti of Egypt, one of the highest religious leaders in Egypt, quoted "Female circumcision is an Islamic practice mentioned in the tradition of the Prophet. We support the practice as a Sunna and sanction it because of its effect on attenuating the sexual desire in women and directing it to the desirable moderation". ${ }^{29}$ In 2013, another Grand Mufti published a review "The Islamic view on female circumcision" where he defined the practice as "a mutilation that endangers the health and social life of women". He also called the legislative organs to take decisive actions against FGM by declaring it a crime. ${ }^{34}$

Currently, the mainstream of religious leaders denounces the continuation of FGM, however, there is a wide discrepancy between their views and those of the local preachers in villages and semi-urban areas who do not condemn and sometimes even support the practice. The beliefs of those preachers can not be detached from their social background. We suppose that if the influential preachers in the community declare their opposition to FGM, significant drops in the prevalence may occur shortly. Since religious preachers in Egypt have a profound impact on shaping the opinions of the Egyptians, future studies should investigate the knowledge and attitude of religious preachers about FGM.

\subsubsection{Hygienic drives}

While the social and religious drives of FGM could be understood within the socio-cultural dogma of the Egyptian society, the hygienic drive seems irrational and stands on no basis. Rural residents in Egypt refer to FGM as "Tahara" or "purification" which reflects the hygienic perception about the practice. It is thought that FGM is associated with the cultural ideals of femininity. These ideals consider the girls purified only after removal of the unfeminine body parts. ${ }^{35}$ Mostly, this drive is attributed to the suboptimal knowledge and attitude regarding FGM.

\section{Study limitations}

The included studies carried potential limitations that may affect the generalizability of the results. For example, data on FGM came from self-reported questionnaires or interviews. Previous studies found incomplete agreement between self-report of FGM and gynecological examination; $79 \%$ and $97 \% .{ }^{36,37}$ In addition, the sampling methods of most of the included studies were vague or unsuitable. Failing to use appropriate sampling techniques can lead to serious forms of bias that result in under- or overestimation of the findings.

Although the EDHSs are widely perceived among the scientific community in Egypt as an accountable indicator for many health issues, including FGM, due to their extensive coverage, classy sampling methods, and large sample size, they are not without limitations. First, these surveys were conducted on ever-married women who had dissimilar socio-demographic characteristics to the never-married, and when the EDHS 2008 included a mixed sample from never- and evermarried women, the overall FGM prevalence dropped to $91 \%(95.2 \%$ in ever-married and $80.5 \%$ in never-married). ${ }^{16}$ Besides, the age category (15-24 years) of the surveyed women represented less than $18 \%$ of the sample. This is despite that the median age of the Egyptians in 2015, for example, was 24.7 years and $35 \%$ of women in this year were under 15 years. ${ }^{38}$ Besides, the included women who were married at the age between 15 and 24 years would be more likely to be circumcised because early marriage and FGM have the same socio-educational risk factors. $^{39}$ 
Further, the EDHSs carry possible sampling and non-sampling errors. While non-sampling errors were difficult to be detected, some sampling errors were documented elsewhere. ${ }^{12-17}$ One more concern about the EDHSs is that the response rates of most surveys were higher than $99 \%$, despite the EDHS lengthy questionnaires for which the interviewers offered no personal incentives for participation. Other studies that investigated FGM among Egyptian samples showed response rates less than $85 \%{ }^{22,40}$ We think that the very high response rates of the EDHSs could be embellished because the Egyptian community is conservative enough to classify the gynecological affairs of women as a taboo that should not be unveiled. So, further clarifications about the response rate and the possibility of non-response bias should be considered in future EDHSs.

Moreover, most studies had several limitations that significantly affect the generalizability of their findings such as investigating a particular category (ever-married, nulliparous women, one village, school or university students, or hospital attendants). Specifically, findings from hospital-based and student-based studies should not be generalized. Public hospitals in Egypt offer primary, secondary, and tertiary health care services with low prices making them the first choice of a significant portion of the destitute people. Therefore, hospital-based studies, mostly conducted on underprivileged populations, can not represent women in Egypt. On the other hand, studies conducted on university students can not be representative for women in the same age category due to two main reasons. First, in comparison to their low to moderately educated counterparts, university students usually come from families with higher social and economic levels. Second, following the campaigns that advised against FGM, an evolving perception linking between FGM and socio-economic shortcomings started to appear. Further, many circumcised women do not consider themselves mutilated and perceive the term FGM as an offense. Therefore, for a young girl looking for a university social life, admitting exposure to FGM could be stigmatizing or offending making them avoid participation in FGM studies which underestimates the real FGM prevalence.

\section{Conclusion}

Based on the vagueness of the implemented sampling methods and the wide variations in the socio-demographic characteristics of the investigated populations, we believe that the answer of the question "What is the prevalence of FGM in Egypt?" is still without a conclusive answer. We also believe that this prevalence is varying across the governorates and even within the same governorate according to the socio-educational status of the residents. Since FGM is primarily a cultural practice, its prevalence should be changing over time. Accordingly, before extracting conclusions from the findings of FGM studies, including the EDHSs, recognizing the sampling methods, the characteristics of the study population, and the time of data collection is mandatory.

We can expect that investigating easily reached samples such as patients and university students is attributed to the lack of sustained funding of FGM research. In this regard, funding future wide-scale epidemiological studies investigating FGM is highly recommended. Prospective studies that aim to evaluate the trends of FGM and assess the impacts of the awareness campaigns on its continuation are needed as well. However, future research should adopt intricate sampling methodologies that minimize the effect of non-response bias and guarantee the representativeness of the whole community. Besides, we believe that detecting the prevalence of FGM in Egypt should not be a responsibility of one research center or one organization, but many research institutions and organizations.

Further, we concluded that low parental education and rural residence are the top risk factors for FGM while religious, social, and hygienic factors are the primary drives behind the continuation of the practice. For a better understanding of the religious drives, future studies should investigate the knowledge and attitude of religious preachers regarding FGM.

Finally, eradicating FGM demands a collaborative approach including community leaders, influential preachers, health care professionals, social workers, national and international institutions, and nongovernmental organizations. Still, we believe that any initiative to eradicate FGM should begin with empowering the social position of women throughout education to make them the key agents of change. Also, adopting a clear religious speech that condemns FGM should be encouraged.

\section{Authors contribution}

AA and AM contributed to the systemic review of articles and manuscript writing.

EE contributed to manuscript writing and proof editing.

\section{Funding}

None.

\section{Declaration of competing interest}

None.

\section{References}

1. World Health Organization. Female Genital Mutilation. A Joint WHO/UNICEF/UNFPA Statement. Geneva: Geneva: WHO; 1997:3-5.

2. World Health Organization. Female Genital Mutilation. Fact Sheet N8 241. WHO; 2000 http://www.who.int/mediacentre/factsheets/fs241/en/ Accessed on 18/10/2018.

3. Aziz F. Gynecologic and obstetric complications of female circumcision. Int J Gynecol Obstet. 1980;17:560-563.

4. Sayed G, Abd El-Aty M, Fadel K. The practice of female genital mutilation in Upper Egypt. Int J Gynecol Obstet. 1996;55:285-291.

5. Koski A, Heymann J. Thirty-year trends in the prevalence and severity of female genital mutilation: a comparison of 22 countries. BMJ Global Health. 2017;2:e000467

6. Koukkula M, Keskimäki I, Koponen P, Mölsä M, Klemetti R. Female genital mutilation/cutting among women of Somali and Kurdish origin in Finland. Birth. 2016;43:240-246.

7. Teixeira A, Lisboa M. Estimating the prevalence of female genital mutilation in Portugal. Publ Health. 2016;139:53-60.

8. Zurynski Y, Phu A, Sureshkumar P, Cherian S, Deverell M, Elliott E. For Australian paediatric surveillance unit female genital mutilation study steering committee. Female genital mutilation in children presenting to Australian pediatricians. Arch Dis Child. 2017;102:509-515.

9. Goldberg H, Stupp P, Okoroh E, Besera G, Goodman D, Danel I. Female genital mutilation/cutting in the United States: updated estimates of women and girls at risk. Publ Health Rep. 2012;131:340-347 2016.

10. Al-Hussaini T. Female Genital Cutting: types, motives and perineal damage in laboring Egyptian women. Med Princ Pract. 2003;12:123-128.

11. Meleigy M. Egypt tightens ban on female genital mutilation after 12 year old girl dies. BMJ. 2007:335:15

12. El-Zanaty F, Hussein E, Shawky G, Way A, Kishor S. Egypt Demographic and Health Survey 1995. Maryland, USA: National Population Council [Arab Republic of Egypt] and Macro International Inc; 1996 Calverton.

13. El-Zanaty F, Way A. Egypt Demographic and Health Survey 2000. Maryland, USA Calverton; 2001 Ministry of Health and Population [Arab Republic of Egypt], National Population Council [Arab Republic of Egypt], and ORC Macro.

14. El-Zanaty F, Way A. Egypt Interim Demographic and Health Survey 2003. Cairo, Egypt Ministry of Health and Population [Arab Republic of Egypt]. National Population Council [Arab Republic of Egypt], El-Zanaty and Associates, and ORC Macro; 2004.

15. El-Zanaty F, Way A. Egypt Demographic and Health Survey 2005. Cairo, Egypt: Ministry of Health and Population [Arab Republic of Egypt]. National Population Council [Arab Republic of Egypt], El-Zanaty and Associates, and ORC Macro; 2006.

16. El-Zanaty F, Way A. Egypt Demographic and Health Survey 2008. Cairo, Egypt: Ministry of Health and Population [Arab Republic of Egypt]. National Population Council [Arab Republic of Egypt], El-Zanaty and Associates, and ORC Macro; 2009.

17. El-Zanaty F, Way A. Egypt Demographic and Health Survey 2014. Maryland, USA Calverton; 2015 Ministry of Health and Population [Arab Republic of Egypt], National Population Council [Arab Republic of Egypt], and ORC Macro.

18. Ahmed M, Shaaban M, Meky H, et al. Psychological impact of female genital mutilation among adolescent Egyptian girls: a cross-sectional study. Eur J Contracept Reprod Health Care. 2017;22:280-285.

19. Ibrahim Z, Ahmed M, Mostafa R. Psychosexual impact of female genital mutilation/ cutting among Egyptian women. Human Androl. 2012;2:36-41.

20. Zayed A, Ali A. Abusing female children by circumcision is continued in Egypt. $J$ Forens Legal Med. 2012;19:196-200. 
21. Moher D, Liberati A, Tetzlaff J, Altman D. PRISMA Group. Preferred reporting items for systematic reviews and meta-analyses: the PRISMA statement. BMJ. 2009;339:2535.

22. Ali H, Arafa A, Shehata N, Fahim A. Prevalence of female circumcision among young women in Beni-Suef, Egypt: a cross sectional study. J Pediatr Adolesc Gynecol. 2018;31:571-574.

23. Badawi M. Epidemiology of female sexual castration in Cairo, Egypt. Presented at the First International Symposium on Circumcision. California: Anaheim; 1989.

24. Arafa A, Elbahrawy R, Shawky S, Abbas A. Epidemiological and gynaecological correlates with female genital mutilation in Beni-Suef University students, crosssectional study. Middle East Fertil Soc J. 2018;23:184-188.

25. Tag-Eldin M, Gadallah M, Al-Tayeb M, Abdel-Aty M, Mansour E, Sallem M. Prevalence of female genital cutting among Egyptian girls. Bull World Health Organ. 2008;86:269-274.

26. Sayed G, Abd El-Aty M, Fadel K. The practice of female genital mutilation in Upper Egypt. Int J Gynecol Obstet. 1996;55:285-291.

27. Dandash K, Refaat A, Eyada M. Female genital mutilation: a descriptive study. J Sex Marital Ther. 2001;27:453-458.

28. Hassanin I, Saleh R, Bedaiwy A, Peterson R, Bedaiwy M. Prevalence of female genital cutting in Upper Egypt: 6 years after enforcement of prohibition law. Reprod Biomed Online. 2008;16:27-31.

29. Assad M. Female circumcision in Egypt: social implications, current research, and prospects for change. Stud Fam Plann. 1980;11:3-6.

30. Abolfotouh S, Ebrahim A, Abolfotouh M. Awareness and predictors of female genital mutilation/cutting among young health advocates. Int $J$ Wom Health. 2015;7:259-269.

31. Van Rossem R, Meekers D, Gage A. Women's position and attitudes towards female genital mutilation in Egypt: a secondary analysis of the Egypt demographic and health surveys, 1995-2014. BMC Publ Health. 2015;15:874.

32. El-Defrawi M, Lotfy G, Dandash K, Refaat A, Eyada M. Female genital mutilation and its psychosexual impact. J Sex Marital Ther. 2001;27:465-473.

33. Mohamed E, Seedhom A, Mahfouz E. Female genital mutilation: current awareness, believes and future intention in rural Egypt. Reprod Health. 2018;15:175.

34. Gomaa A. The Islamic view on female circumcision. Afr J Urol. 2013;19:123-126

35. World Health Organization. Female Genital Mutilation. Fact Sheets. WHO; 2018 http:// www.who.int/mediacentre/factsheets/fs241/en/ Accessed on 25/10/2018.

36. Morison L, Scherf C, Ekpo G, et al. The long-term reproductive health consequences of female genital cutting in rural Gambia: a community based survey. Trop Med Int Health. 2001;6:643-653.

37. Snow R, Slanger T, Okonofua F, Oronsaye F, Wacker J. Female genital cutting in southern urban and peri-urban Nigeria: self-reported validity, social determinants and secular decline. Trop Med Int Health. 2002;7:91-100.
38. United Nations (UN) development programme. Human development reports. http:// hdr.undp.org/en/content/human-development-index-hdi Accessed on 19/10/2018.

39. Nour N. Child marriage: a silent health and human rights issue. Rev Obstet Gynecol. 2009;2:51-56

40. Abdel Raheem T, Eltahalawi S, Abo Raia N, Elsary A, Ibrahem K. The effect of female genital mutilation on couple sexual function. Int J Community Med Public Health. 2018;5:905-911.

41. Yount K. Symbolic gender politics, religious group identity, and the decline in female genital cutting in Minya, Egypt. Soc Forces. 2004;82:1063-1090.

42. Elnashar A, Abdelhady R. The impact of female genital cutting on health of newly married women. Int J Gynaecol Obstet. 2007;97:238-244.

43. Emam E, El-Maghawri A, Labeeb S. Cultural awareness about female genital mutilation among female employees of Minia University. J Am Sci. 2011;7:611-617.

44. Habib S, Abdel Azim E, Fawzy I, Kamal N, El Sherbini A. Prevalence and effects of violence against women in a rural community in Minia governorate, Egypt. $J$ Forensic Sci. 2011;56:1521-1527.

45. Rasheed S, Abd-Ellah A, Yousef F. Female genital mutilation in Upper Egypt in the new millennium. Int J Gynaecol Obstet. 2011;114:47-50.

46. Shaeer O, Shaeer E. The Global Online Sexuality Survey: public perception of female genital cutting among internet users in the Middle East. J Sex Med. 2013;10:2904-2911.

47. Hassanin I, Shaaban O. Impact of the complete ban on female genital cutting on the attitude of educated women from Upper Egypt toward the practice. Int $J$ Gynecol Obstet. 2013;120:275-278.

48. Arafa E, Abdelghany A, Madkour N, Nossair W, Mohamed E. Survey study of acute and long term effects of female genital mutilation among women in Sharkia Governorate. Open J Obstet Gynecol. 2014;4:874-880.

49. Shaheen H, Hegazy N, Ali M. The current situation about female genital mutilation among circumcised and uncircumcised women in Manwahla family health unit, ElBagour, Menofia. Menoufia Med J. 2016;29:1100-1105.

50. Abdel-Aleem M, Elkady M, Hilmy Y. The relationship between female genital cutting and sexual problems experienced in the first two months of marriage. Int $J$ Gynecol Obstet. 2016;132:305-308.

51. Modrek S, Sieverding M. Mother, daughter, doctor: medical professionals and mothers' decision making about female genital cutting in Egypt. Int Perspect Sex Reprod Health. 2016;42:81-92.

52. Yousef F, Hamed A, Mostafa N. Female genital cutting: prevalence, knowledge, and attitudes of Sohag University level students, Upper Egypt. The Egypt. J Community Med. 2017;35:17-25.

53. Mitwaly A, Abd El Aal D, Aziz P, Hassanin A, Abbas A. A recent look for the implication and attitude of practicing female genital mutilation in Upper Egypt: a cross sectional study. Int J Reprod Contracept Obstet Gynecol. 2017;6:4224-4249. 